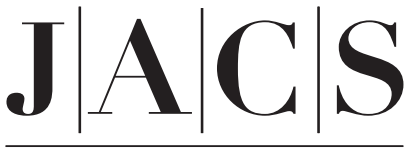

A R T I C L E S

Published on Web 09/05/2008

\title{
Catalytic Tuning of a Phosphinoethane Ligand for Enhanced C-H Activation
}

\author{
Thomas R. Cundari, ${ }^{\star}$ J. Oscar C. Jimenez-Halla, ${ }^{\S}$ Glenn R. Morello, and \\ Sridhar Vaddadi \\ Department of Chemistry and Center for Advanced Scientific Computing and Modeling \\ (CASCaM), University of North Texas, P.O. Box 305070, Denton, Texas 76203-5070
}

Received April 29, 2008; E-mail: tomc@unt.edu

\begin{abstract}
Hydrogen atom abstraction (HAA) from 1,4-cyclohexadiene (CD-H) by (dtbpe)Ni(NAr) to form a $\mathrm{Ni}^{\mathrm{l}}$-amide, (dtbpe)Ni(NHAr), and cyclohexadienyl radical is calculated to be thermodynamically reasonable, $\Delta H_{\text {HAA }}(\mathrm{dtbpe})=-1.3 \mathrm{kcal} / \mathrm{mol}$, dtbpe $=$ bis(di-tert-butylphosphino)ethane, $\mathrm{Ar}=2,6$-diisopropylphenyl. However, radical rebound to form a metal-bound amine is highly endothermic $\left(\Delta H_{\text {reb }}(\mathrm{dtbpe})=+25.1 \mathrm{kcal} /\right.$ $\mathrm{mol})$. Analysis of bond enthalpies indicates that weakening of the $\mathrm{Ni}-\mathrm{N}$ bond $(\mathrm{Ni}-$ amide $\rightarrow \mathrm{Ni}-$ amine $)$ upon radical rebound is not compensated by the weak $\mathrm{C}-\mathrm{N}$ bond formed. Hence, a ligand was sought that would enhance the metal-amine bond strength while diminishing the metal-amide bond strength. Reaction of (dfmpe)Ni(NAr) with CD-H was thus analyzed, dfmpe = bis(di(trifluoromethyl)phosphino)ethane. While there is a small change in the thermodynamics of HAA $\left(\Delta H_{\mathrm{HAA}}(\mathrm{dfmpe})=-5.7 \mathrm{kcal} / \mathrm{mol}\right)$, there is a profound change in the rebound step $\left(\Delta H_{\text {reb }}(\mathrm{dfmpe})=-7.8 \mathrm{kcal} / \mathrm{mol}\right)$ upon replacing dtbpe by dfmpe. Regeneration of the nitrene active species by reaction of $\mathrm{ArN}_{3}$ with the metal-bound product is calculated to be highly exothermic, $\Delta H_{\text {reg }}=-36.7 \mathrm{kcal} / \mathrm{mol}$. Two candidates for a precatalyst, (dfmpe) Ni(COD) and (dfmpe) Ni(bpy), COD = 1,5-cyclooctadiene and bpy =2,2'-bipyridine, were calculated to undergo highly exothermic reactions with $\mathrm{ArN}_{3}$ to form the nitrene active species. The calculated enthalpic barrier for HAA of $\mathrm{CD}-\mathrm{H}$ by (dfmpe) $\mathrm{Ni}(\mathrm{NAr})$ is $21.3 \mathrm{kcal} / \mathrm{mol}$. Hence, consideration of the computed thermodynamics and kinetics suggests that nickel-nitrenes with fluorinated phosphine supporting ligation are promising candidates for catalytic amination of $\mathrm{C}-\mathrm{H}$ bonds.
\end{abstract}

\section{Introduction}

Despite two decades having passed since the first demonstration of hydrocarbon $\mathrm{C}-\mathrm{H}$ bond activation by well-characterized organometallic complexes, selective catalytic functionalization of unactivated hydrocarbons under mild conditions via $\mathrm{C}-\mathrm{H}$ bond activation pathways remains a subject of considerable interest and practical importance. ${ }^{1,2}$ Substantial experimental and computational research has focused on delineation of different mechanisms by which metal complexes activate carbon-hydrogen bonds, including $\sigma$-bond metathesis, oxidative addition, oxidative hydrogen migration, electrophilic substitution, acid/base, and radical pathways. From the foregoing research, a wealth of

\footnotetext{
${ }^{\S}$ Present address: Department of Chemistry, University of Girona, Girona, Spain.

(1) (a) Fairlamb, I. J. S. Annu. Rep. Prog. Chem. B 2006, 102, 50. (b) Goj, L. A.; Gunnoe, T. B. Curr. Org. Chem. 2005, 9, 671. (c) Lersch, M.; Tilset, M. Chem. Rev. 2005, 105, 247. (d) Goldman, A. S.; Goldberg, K. I. Organometallic $C-H$ Bond Activation; American Chemical Society: Washington, DC, 2004. (e) Labinger, J. A.; Bercaw, J. E. Nature 2002, 417, 507. (f) Fekl, U.; Goldberg, K. I. Adv. Inorg. Chem. 2003, 54, 259. (g) Crabtree, R. H. J. Organomet. Chem. 2004. $689,4083$.

(2) (a) Sadow, AaronD.; Tilley, T. D. Presented at the 224th ACS National Meeting, Aug 18-22, 2002, Boston, MA; INOR-563. (b) Sadow, A. D.; Tilley, T. D. J. Am. Chem. Soc. 2005, 127, 643. (c) Goldman, A. S.; Roy, A. H.; Huang, Z.; Ahuja, R.; Schinski, W.; Brookhart, M. Science 2006, 312, 257. (d) Chen, H.; Schlecht, S.; Semple, T. C. Hartwig, J. F. Science 2000, 287, 1995. (e) Webster, C. E.; Fan, Y.; Hall, M. B.; Kunz, D.; Hartwig, J. F. J. Am. Chem. Soc. 2003, 125, 858.
}

information has been deduced about the stereoelectronic factors that control and delineate the various activation mechanisms. ${ }^{1}$ What has also emerged from experimental and computational studies is that, while certain transition metal systems are competent for one or perhaps more steps within a catalytic cycle, the identification of metal complexes that are competent for the full array of steps that comprise a $\mathrm{C}-\mathrm{H}$ bond functionalization catalytic cycle is quite difficult. For example, early metal (Group 4 and 5)-imido complexes $\left(\mathrm{L}_{n} \mathrm{M}=\mathrm{N}-\mathrm{Si}^{\mathrm{t}} \mathrm{Bu}_{3}\right)$ are impressive in their avidity for $\mathrm{C}-\mathrm{H}$ bond activation via a $\left[2_{\sigma}+2_{\pi}\right]$ mechanism, ${ }^{3}$ but the resultant amides $\left(\mathrm{L}_{n} \mathrm{M}(\mathrm{R})\left(\mathrm{N}(\mathrm{H}) \mathrm{Si}^{\mathrm{t}} \mathrm{Bu}_{3}\right)\right)$ are "too stable", being unable to generate amine $\left(\mathrm{RN}(\mathrm{H}) \mathrm{Si}^{\mathrm{t}} \mathrm{Bu}_{3}\right)$ product via reductive elimination.

(3) (a) Cummins, C. C.; Baxter, S. M.; Wolczanski, P. T. J. Am. Chem. Soc. 1988, 110, 8731. (b) Cummins, C. C.; Schaller, C. P.; Van Duyne, G. D.; Wolczanski, P. T.; Chan, A. W. E.; Hoffmann, R. J. Am. Chem. Soc. 1991, 113, 2985. (c) Schaller, C. P.; Wolczanski, P. T. Inorg. Chem. 1993, 32, 131. (d) Bennett, J. L.; Wolczanski, P. T. J. Am. Chem. Soc. 1994, 116, 2179. (e) Schaller, C. P.; Bonanno, J. B.; Wolczanski, P. T. J. Am. Chem. Soc. 1994, 116, 4133. (f) Schaller, C. P.; Cummins, C. C.; Wolczanski, P. T. J. Am. Chem. Soc. 1996, 118, 591. (g) Bennett, J. L.; Wolczanski, P. T. J. Am. Chem. Soc. 1997, 119, 10696. (h) Schafer, D. F.; Wolczanski, P. T. J. Am. Chem. Soc. 1998, 120, 4881. (i) Slaughter, L. M.; Wolczanski, P. T.; Klinckman, T. R.; Cundari, T. R. J. Am. Chem. Soc. 2000, 122, 7953. (j) Cundari, T. R.; Klinckman, T. R.; Wolczanski, P. T. J. Am. Chem. Soc. 2002, 124, 1481. (k) Cundari, T. R. J. Am. Chem. Soc. 1992, $114,10557$.

(4) Bourget-Merle, L.; Lappert, M. F.; Severn, J. R. Chem. Rev. 2002, 102,3031 . 
Late transition metal (i.e., Groups 8-11)-nitrene complexes are profitable targets for development of novel hydrocarbon functionalization catalysts. First, new supporting ligands such as $\beta$-diketiminates ${ }^{4}$ and bulky bis-phosphines ${ }^{5}$ have led to the synthesis and structural characterization of late transition metal-nitrenes. Notable examples include $3 \mathrm{~d}$ nitrenes of Fe, ${ }^{6}$ $\mathrm{Co},{ }^{7}$ and $\mathrm{Ni}^{5 a, b, f, 8}$ to augment earlier examples incorporating heavier metals, e.g., $\mathrm{Cp} * \mathrm{Ir}=\mathrm{N}^{t} \mathrm{Bu}^{9}$ and (cumene) $\mathrm{Os}=\mathrm{N}^{t} \mathrm{Bu} .{ }^{10}$ Second, the isovalent relationship of nitrene (NR) and oxo (O) moieties suggests useful biological analogies, in particular for iron $^{11}$ and copper. ${ }^{12}$ Third, the ready synthesis of late metal-nitrene complexes via group-transfer reagents such as organic azides suggest that (re)generation of nitrene active species within a catalytic cycle should be kinetically and thermodynamically feasible. ${ }^{6-8}$ Fourth, Ni-mediated nitrene transfer has not, to our knowledge, been experimentally observed for aliphatic or aromatic $\mathrm{C}-\mathrm{H}$ bonds, but $\mathrm{NR}$ transfer to substrates such as olefins and $\mathrm{CO}$ has been reported for the late $3 \mathrm{~d}$ metals. $^{5-8,13-16}$ Warren's group $^{8}$ has isolated a $\mathrm{Ni}(\beta$ diketiminate)nitrene complex that can effect $\mathrm{C}-\mathrm{H}$ activation of 1,4-cyclohexadiene (CD-H). Amination by late metal catalysts (notably $\mathrm{Pd}^{17}$ and $\mathrm{Cu}^{18}$ ) is established in organic synthesis but involves initial functionalization of a hydrocarbon to produce a more reactive surrogate (e.g., organic chloride). Direct amination of hydrocarbons is more desirable from an atomeconomical viewpoint.

Computational chemistry has greatly aided the understanding of carbon-hydrogen bond activation mechanisms, from the

(5) (a) Mindiola, D. J.; Hillhouse, G. L. J. Am. Chem. Soc. 2001, 123, 4623. (b) Melenkivitz, R.; Mindiola, D. J.; Hillhouse, G. L. J. Am. Chem. Soc. 2002, 124, 3846. (c) Mindiola, D. J.; Hillhouse, G. L. Chem. Commun. 2002, 17, 1840. (d) Mindiola, D. J.; Hillhouse, G. L. J. Am. Chem. Soc. 2002, 124, 9976. (e) Waterman, R.; Hillhouse, G. L. Organometallics 2003, 23, 5182. (f) Waterman, R.; Hillhouse, G. L. J. Am. Chem. Soc. 2003, 125, 13350. (g) Kitiachvili, K. D.; Mindiola, D. J.; Hillhouse, G. L. J. Am. Chem. Soc. 2004, 126, 10554.

(6) (a) Eckert, N. A.; Vaddadi, S.; Stoian, S.; Flaschenriem, C. J.; Cundari, T. R.; Munck, E.; Holland, P. L. Angew. Chem., Int. Ed. 2006, 45, 6868. (b) Bach, T; Korker, C. Eur. J. Org. Chem. 1998, 5, 1033. (c) Verma, A. K.; Nazif, T. N.; Achim, C.; Lee, S. C. J. Am. Chem. Soc. 2000, 122, 11013. (d) Brown, S. D.; Betley, T. A.; Peters, J. C. J. Am. Chem. Soc. 2003, 125, 322. (e) Betley, T. A.; Peters, J. C. J. Am Chem. Soc. 2003, 125, 10782. (f) Jensen, M. P.; Mehn, N. P.; Que, L. Angew. Chem., Int. Ed. 2003, 42, 4357. (g) Brown, S. D.; Peters, J. C. J. Am. Chem. Soc. 2004, 126, 4538. (h) Bart, S. C.; Lobkovsky, E.; Bill, E.; Chirik, P. J. J. Am. Chem. Soc. 2006, 128, 5302.

(7) (a) Thyagarajan, S.; Shay, D. T.; Incarvito, C. D.; Rheingold, A. L.; Theopold, K. H. J. Am. Chem. Soc. 2003, 125, 4440. (b) Hu, X.; Meyer, K. J. Am. Chem. Soc. 2004, 126, 16322. (c) Jenkins, D. M.; Betley, T. A.; Peters, J. C. J. Am. Chem. Soc. 2002, 124, 11238.

(8) Kogut, E.; Wiencko, H. L.; Zhang, L.; Cordeau, D.; Warren, T. H. J. Am. Chem. Soc. 2005, 127, 11248.

(9) Glueck, D. S.; Wu, J.; Hollander, F. J.; Bergman, R. G. J. Am. Chem. Soc. 1991, 113, 2041.

(10) Michelman, R. I.; Andersen, R. A.; Bergman, R. G. J. Am. Chem. Soc. 1991, 113, 5100.

(11) Jensen, M. P.; Mehn, M. P.; Que, L. Angew. Chem., Int. Ed. 2003 42, 4357.

(12) Yoshizawa, K.; Shiota, Y. J. Am. Chem. Soc. 2006, 128, 9873.

(13) Vedernikov, A. N.; Caulton, K. G. Chem. Commun. 2004, 2, 162.

(14) Badiei, Y. M.; Krishnaswamy, A.; Melzer, M. M.; Warren, T. H. J. Am. Chem. Soc. 2006, 128, 15056.

(15) Li, Z.; Capretto, D. A.; Rahaman, R.; He, Z. Angew. Chem., Int. Ed. 2007, 46, 5184.

(16) Li, Z.; Capretto, D. A.; Rahaman, R.; He, Z. J. Am. Chem. Soc. 2007, 129,12058

(17) Stuermer, R. Organic Synthesis Highlights V; Wiley-VCH: Weinheim, 2003; p 22. Muci, A. R.; Buchwald, S. L. Top. Curr. Chem. 2002, 219, 131. Hartwig, J. F. Comprehensive Coordination Chemistry II; Elsevier: Amsterdam, 2004; Vol. 9, p 369.

(18) Shafir, A.; Buchwald, S. L. J. Am. Chem. Soc. 2006, 128, 8742. classic studies of Hoffmann ${ }^{19,20}$ to more recent works by Goddard, Oxgaard and co-workers ${ }^{21}$ (to mention one from among many possible excellent examples). What is less modeled are the subsequent steps that close the catalytic cycles for hydrocarbon functionalization. Furthermore, computational chemistry has been generally reactive in terms of rationalizing known catalysts as opposed to proactive in identifying novel systems that warrant serious experimental consideration for catalytic hydrocarbon functionalization. In the present research, a theoretical study of the amination of CD-H by (dtbpe)Ni(NAr) (Ar = 2,6-diisopropylbenzene) has been made. Furthermore, computations are used to predict the change in energetics by changing the substituents on the chelating phosphine from tertbutyl to trifluoromethyl groups.

\section{Computational Methods}

The Gaussian 03 package $^{22}$ was used for all calculations described herein. Specifically, a hybrid quantum/molecular mechanical (QM/MM) approach, employing the ONIOM ${ }^{23}$ methodology, was used to model as realistic as possible chemical systems. The utility of QM/MM approaches for inorganic chemistry has recently been reviewed. ${ }^{24}$ The B3LYP density functional in conjunction with the 6-31G(d) all-electron basis set was used for the quantum region, which comprised the metal, the ligating atoms, the $\mathrm{CH}_{2} \mathrm{CH}_{2}$ backbone atoms of the bis-phosphine supporting ligands, the six carbons of the Ar (2,6-diisopropylphenyl)-nitrene substituent and the three hydrogen atoms directly attached to these aromatic carbons (Figure 1). Any remaining atoms were modeled with the Universal Force Field (UFF) ${ }^{25}$ For model complexes employing the dtbpe (dtbpe = bis(di-tert-butylphosphino)ethane) ligand, the tert-butyl groups were included in the MM region and thus modeled with the UFF. To faithfully model the electronwithdrawing nature of the trifluoromethyl groups, $\mathrm{CF}_{3}$ was included in the QM region of bis(di(trifluoromethyl)phosphino)ethane (dfmpe) models. $^{26}$ The 1,4-cyclohexadiene (CD-H) substrate was modeled quantum mechanically (B3LYP/6-31G(d)) as were cyclooctadiene, bipyridine, $\mathrm{CO}$, and $\mathrm{ArN}_{3}$ (except the ${ }^{\mathrm{i}} \mathrm{Pr}$ groups). Solvent effects were neglected.

All stationary points were of singlet spin multiplicity (unless explicitly mentioned otherwise) and fully geometry optimized using gradient methods without symmetry constraint. The calculated energy Hessian confirmed the stationary points as minima (no imaginary frequencies) or transition states (one imaginary frequency). The thermochemistry of the reaction was determined at 1 atm and 298.15 K using unscaled ONIOM(B3LYP/6-31G(d):UFF) frequencies. Intrinsic reaction coordinates were followed from transition states to reactants and products to confirm the nature of the calculated transition states.

\section{Results and Discussions}

The reaction sequence studied for hydrocarbon functionalization is shown in eqs 1 and $2(\mathrm{P} \sim \mathrm{P}$ denotes a chelating bis-

(19) Saillard, J. Y.; Hoffmann, R. J. Am. Chem. Soc. 1984, 106, 2006.

(20) Rabaâ, H.; Saillard, J. Y.; Hoffmann, R. J. Am. Chem. Soc. 1986, $108,4327$.

(21) (a) Oxgaard, J.; Periana, R. A.; Goddard, W. A., III J. Am. Chem. Soc. 2004, 126, 11658. (b) Oxgaard, J.; Muller, R. P.; Goddard, W. A.; Periana, R. A. J. Am. Chem. Soc. 2004, 126, 352.

(22) Frisch, M. J.; et al. Gaussian 03, Revision C.02; Gaussian Inc.: Wallingford, CT, 2004.

(23) Svensson, M.; Humbel, S.; Froese, R. D. J.; Matsubara, T.; Sieber, S.; Morokuma, K. J. Phys. Chem. 1996, 100, 1935.

(24) Bo, C.; Maseras, F. J. Chem. Soc., Dalton Trans. 2008, 2911-2919.

(25) (a) Casewit, C. J.; Colwell, K. S.; Rappé, A. K. J. Am. Chem. Soc. 1992, 114, 10035. (b) Rappé, A. K.; Casewit, C. J.; Colwell, K. S.; Goddard, W. A., III; Skiff, W. M. J. Am. Chem. Soc. 1992, 114, 10024.

(26) Bennett, B. L.; White, S.; Hodges, B.; Rodgers, D.; Lau, A.; Roddick, D. M. J. Organomet. Chem. 2003, 679, 65. 


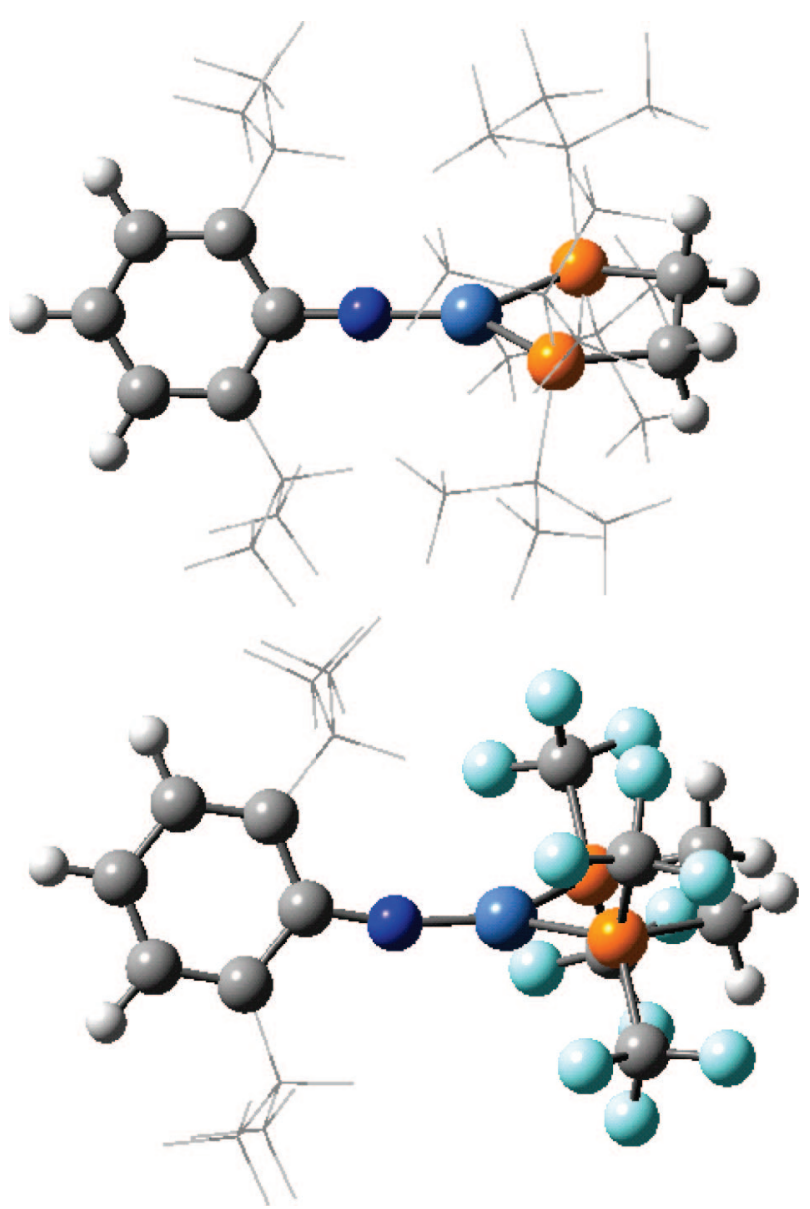

Figure 1. QM/MM-optimized geometries of (dtbpe)NiNAr (top) and (dfmpe)NiNAr (bottom). MM atoms are shown in wireframe, and the remainder is modeled with QM (B3LYP/6-31G (d)) methods.

phosphine coligand). In a study of $\mathrm{Ru}-\mathrm{X}(\mathrm{X}=$ amide $)$ complexes, ${ }^{27}$ the diminution of the metal-nitrogen bond strength upon $\mathrm{C}-\mathrm{H}$ addition was found to be an important factor in determining the thermodynamic feasibility of $\mathrm{C}-\mathrm{H}$ bond functionalization. Thus, a two-step mechanism (i.e., hydrogen atom abstraction (HAA) from a hydrocarbon and then rebound of the hydrocarbyl radical) was studied to delineate the thermodynamic costs for the conversion of the nickel-nitrogen bond from a multiple bond (nitrene) to a formally single bond (amide) and then to a dative $\mathrm{Ni} \leftarrow \mathrm{N}$ bond (amine product).

$$
\begin{gathered}
(\mathrm{P} \sim \mathrm{P}) \mathrm{Ni}(\mathrm{NAr})+\mathrm{CD}-\mathrm{H} \rightarrow(\mathrm{P} \sim \mathrm{P}) \mathrm{Ni}(\mathrm{NHAr})+\mathrm{CD} \\
\text { hydrogen atom abstraction }
\end{gathered}
$$

$$
\begin{gathered}
(\mathrm{P} \sim \mathrm{P}) \mathrm{Ni}(\mathrm{NHAr})+\mathrm{CD} \rightarrow(\mathrm{P} \sim \mathrm{P}) \mathrm{Ni}(\mathrm{NH}(\mathrm{CD}) \mathrm{Ar}) \\
\text { radical rebound }
\end{gathered}
$$

1. Amination of 1,4-Cyclohexadiene by (dtbpe)Ni(NAr). Amination of $\mathrm{CD}-\mathrm{H}$ by (dtbpe)Ni(NAr) ${ }^{5 \mathrm{a}}$ was studied using QM/ MM methods. The choice of CD-H as substrate was motivated by experimental reports. ${ }^{6 a, 8}$ Holland's group has shown that steric factors cannot be discounted in $\mathrm{C}-\mathrm{H}$ bond activation by late metal nitrenes, thus inspiring the study of full ligand models. $^{6 \mathrm{a}}$

a. Thermodynamics of Amination. Amination of CD-H by (dtbpe) $\mathrm{Ni}(\mathrm{NAr})$ to form the $\mathrm{Ni}^{0}$-ligated product (dtbpe) $\mathrm{Ni}$ -

(27) Conner, D.; Jayaprakash, K. N.; Cundari, T. R.; Gunnoe, T. B. Organometallics 2004, 23, 2724.

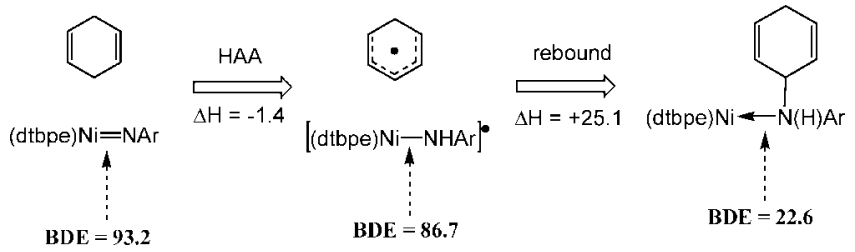

Figure 2. Calculated thermodynamics of amination of $\mathrm{CD}-\mathrm{H}$ by (dtbpe)$\mathrm{Ni}(\mathrm{NAr})$ : hydrogen atom abstraction (HAA) and radical rebound. Calculated $\mathrm{Ni}-\mathrm{N}$ bond dissociation enthalpies (BDEs), in $\mathrm{kcal} / \mathrm{mol}$, are indicated. Calculated at B3LYP/6-31G(d):UFF level of theory.

( $\mathrm{NH}(\mathrm{CD}) \mathrm{Ar})$ is endothermic $\left(\Delta H_{\mathrm{am}}=+23.7 \mathrm{kcal} / \mathrm{mol}\right)$ (Figure 2 ). The computed result is perhaps not surprising, as one would have expected $\mathrm{C}-\mathrm{H}$ bond activation, if feasible, to have been reported in the extensive reactivity studies of (dtbpe)Ni(NAr) and related complexes. ${ }^{5}$

b. Thermodynamics of Hydrogen Atom Abstraction. Despite the thermodynamic unfavorability of $\mathrm{CD}-\mathrm{H}$ amination by (dtbpe)Ni(NAr), it is instructive to evaluate a hypothetical twostep mechanism: HAA of CD-H followed by rebound of the $\mathrm{CD}$ radical. Hydrogen atom abstraction to form a $\mathrm{Ni}^{I}$-amide (doublet spin state), (dtbpe)Ni(NHAr), is calculated to be exothermic, $\Delta H_{H A A}($ dtbpe $)=-1.4 \mathrm{kcal} / \mathrm{mol}$. This is implicitly reasonable in that there is a rough balance in the bond strengths of the $\mathrm{N}-\mathrm{H}$ bond being formed (calculations indicate a value of $79.1 \mathrm{kcal} / \mathrm{mol}$ for ${ }^{3} \mathrm{NAr}+{ }^{2} \mathrm{H} \rightarrow{ }^{2} \mathrm{NHAr}$ using the same ONIOM methods applied to the nickel complexes) and the $\mathrm{C}-\mathrm{H}$ bond being cleaved (experimentally $\mathrm{CD}-\mathrm{H} \rightarrow \mathrm{CD}+\mathrm{H}$ is quoted as $76 \pm 1 \mathrm{kcal} / \mathrm{mol}$ and calculated as $71.2 \mathrm{kcal} / \mathrm{mol}$ using B3LYP/6-31G(d) methods). ${ }^{28}$ Thus, the deciding factor in the thermodynamics of eq 1 (HAA) is expected to be the $\pi$-bond energy of the nickel-nitrene active species, assuming a formal reduction in the $\mathrm{Ni}-\mathrm{N}$ bond order from two (nitrene) to one (amide), which is addressed in the following section.

c. Nickel-Nitrogen Bond Enthalpies. Model calculations are performed to quantify the change in nickel-nitrogen bond enthalpy upon conversion of the nitrene to the amide complex. The nickel-nitrene bond dissociation enthalpy (BDE) is calculated from the reaction (dtbpe) Ni(NAr) $\rightarrow($ dtbpe $) \mathrm{Ni}+{ }^{3} \mathrm{NAr}$ and a value of $93.2 \mathrm{kcal} / \mathrm{mol}$ obtained. The aryl-nitrene is calculated in its triplet ground state ${ }^{29}$ (dtbpe)Ni is predicted to have a singlet ground state. The Ni-amide BDE of $86.7 \mathrm{kcal} /$ mol is estimated in a similar fashion $\left({ }^{2}\right.$ (dtbpe) Ni(NHAr) $\rightarrow$ (dtbpe) $\mathrm{Ni}+{ }^{2} \mathrm{NHAr}$ ).

The calculated difference in $\mathrm{Ni}=\mathrm{NAr}$ and $\mathrm{Ni}-\mathrm{NHAr}$ BDEs yields an estimate of the $\mathrm{Ni}-\mathrm{N} \pi$-bond enthalpy for (dtbpe) Ni(NAr) of $6.5 \mathrm{kcal} / \mathrm{mol}$. A weak $\pi$-bond is expected for a metal complex with a high d-electron count $\left(\mathrm{d}^{10}\right.$ if one assumes a neutral nitrene ligand; $\mathrm{d}^{8}$ if an imide $\mathrm{NAr}^{2-}$ description is utilized). A weak $\mathrm{Ni}-\mathrm{N} \pi$-bond is also consistent with the chemistry of Hillhouse's complexes. ${ }^{5}$ Simulations thus indicate that the thermoneutrality of the HAA step is due to the small

(28) Using the reported gas-phase enthalpies of formation of 1,4-cyclohexadiene $(24-26 \mathrm{kcal} / \mathrm{mol})$, the cyclohexadienyl radical $(45.7 \mathrm{kcal} /$ $\mathrm{mol})$, and the hydrogen atom $(52.1 \mathrm{kcal} / \mathrm{mol})$ indicates a $\mathrm{C}-\mathrm{H}$ bond energy in 1,4-cyclohexadiene of $72-74 \mathrm{kcal} / \mathrm{mol}$. The enthalpy of formation of the cyclohexadienyl radical is taken from the literature ( Nicovich, J. M.; Ravishankara, J. Phys. Chem. 1984, 88, 2534), while the other values come from the NIST Webbook (http://webbook. nist.gov).

(29) Borden, W. T.; Gritsan, N. P.; Hadad, C. M.; Karney, W. L.; Kemnitz, C. R.; Platz, M. S. Acc. Chem. Res. 2000, 33, 765. 


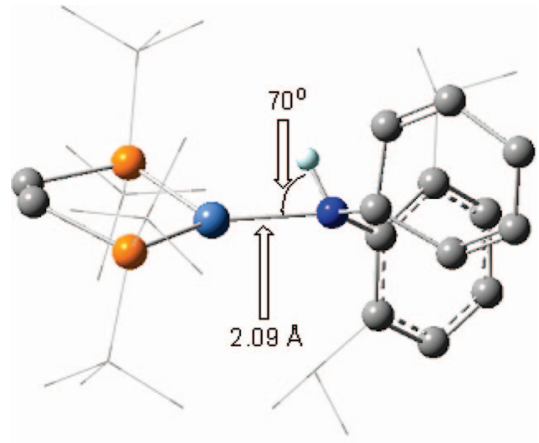

Figure 3. Calculated structure of metal-bound amine product, (dtbpe)$\mathrm{Ni}(\mathrm{NH}(\mathrm{CD}) \mathrm{Ar})$. Hydrogen atoms (except for that attached to amine nitrogen) are omitted for clarity.

difference in the $\mathrm{X}-\mathrm{H}$ bonds formed $(\mathrm{X}=\mathrm{N})$ and broken $(\mathrm{X}$ $=\mathrm{C}$ ) combined with the very small nickel-nitrogen $\pi$-bond energy.

d. Thermodynamics of Radical Rebound. Radical rebound is calculated to be markedly endothermic $\left(\Delta H_{\text {reb }}(\right.$ dtbpe $)=$ $+25.1 \mathrm{kcal} / \mathrm{mol}$ ). Rebound entails formation of a $\mathrm{N}-\mathrm{C}$ bond for the amine product, $\mathrm{NH}(\mathrm{CD})$ Ar. At the metal center, radical rebound causes a reduction in the nickel-nitrogen bond order from a formal single bond (amide) to a dative bond (amine). The $\mathrm{N}-\mathrm{C}$ bond is calculated to be very weak for this bulky amine: $\operatorname{BDE}(\operatorname{Ar}(\mathrm{H}) \mathrm{N}-\mathrm{CD})=39.0 \mathrm{kcal} / \mathrm{mol}$. Evidence for the steric conflict in (dtbpe) Ni(NH(CD)Ar) can be seen in the relatively long $\mathrm{Ni}-\mathrm{N}$ bond of $2.09 \AA$. The average and standard deviation for acyclic $\mathrm{Ni}-\mathrm{N}_{\text {amine }}$ bond lengths derived from the Cambridge Structural Database $\left(\mathrm{CSD}^{30}\right)$ for four-coordinate nickel (three-coordinate complexes are not available) is $1.96 \pm$ $0.05 \AA$ for 31 observations. Of course, the effect of formal oxidation state cannot be ignored, as the crystallographic examples are all formally $\mathrm{Ni}(\mathrm{II})$. The distortion of the amine $\mathrm{N}$ from normal tetrahedral coordination, specifically a very small $\mathrm{Ni}-\mathrm{N}-\mathrm{H}$ angle of $70^{\circ}$ (Figure 3), also indicates the steric congestion at the nickel center in (dtbpe) Ni(NH(CD)Ar).

Combining the calculated $\mathrm{Ni}$-amide BDE of $86.7 \mathrm{kcal} / \mathrm{mol}$ with the corresponding $\mathrm{Ni}$-amine BDE (22.6 kcal/mol) implicates the change of metal-ligand bond enthalpy as a key factor in the thermodynamic unfavorability of the rebound step for the (dtbpe)Ni system. While less bulky hydrocarbyl radicals might have an enhanced $\mathrm{C}-\mathrm{N}$ bond enthalpy, it is likely that such substrates will also entail stronger $\mathrm{C}-\mathrm{H}$ bond energies, which would then unfavorably impact the thermodynamics of the HAA step.

The results, although not supportive of a potent hydrocarbon (dtbpe)Ni-based amination catalyst, are instructive. The present calculations, when combined with studies of Ru complexes, ${ }^{27}$ indicate that a possible route to thermodynamic feasibility lies in identification of ligand modifications that enhance the metal-amine bond strength while diminishing the metal-amide bond strength. Such a modification could also benefit HAA by providing more thermodynamic driving force, assuming that the nickel-nitrene bond energy remains unchanged upon chemical modification. These bond enthalpy changes are, however, hard to predict a priori, and hence further QM/MM simulations were carried out to address these hypotheses.

(30) The analysis was limited to neutral complexes in which the $\mathrm{Ni}-\mathrm{N}$ amine bond was acylic and the R factor was $>10 \%$. (a) Allen, F. H.; Taylor, R. Chem. Soc. Rev. 2004, 33, 463. (b) Allen, F. H.; Davies, J. E.; Galloy, J. J.; Johnson, O.; Kennard, O.; Macrae, C. F.; Mitchell, E. M.; Smith, J. M.; Watson, D. G. J. Chem. Comput. Sci. 1991, 187.
2. Amination of 1,4-Cyclohexadiene by (dfmpe)Ni(NAr). In the search for a synthetically feasible, bis-phosphine $\mathrm{Ni}$-nitrene to catalytically aminate hydrocarbons, two major criteria were used to ensure maximum experimental relevance. First, it was assumed that the phosphine must be a chelating bis(phosphino)ethane, given the prevalence of chelating ligation (e.g., $\beta$-diketiminates, dtbpe, tris(phosphino)borates, and tris(pyrazolyl)borates $)^{5-8}$ in the experimental literature of late transition metal-nitrenes. Such a criterion also helps to maintain close similarity to complexes ${ }^{5}$ with demonstrated nitrene transfer chemistry. Second, the ligand modification must have plausible synthetic precursors, preferably complexes with formally $\mathrm{Ni}^{0}$. This requirement implies $\mathrm{L}_{n} \mathrm{Ni}-\mathrm{LL}$ synthons in which LL is a labile ligand, which could be readily displaced by organic azides (e.g., $\mathrm{AdN}_{3}$ or $\mathrm{ArN}_{3}$ ) to form the required nickel-nitrene.

Using the above criteria, plus the implication derived from the dtbpe simulations that a stronger nickel-amine bond was needed to make the rebound step exothermic, a survey of the literature and the $\mathrm{CSD}^{30}$ was conducted for plausible targets. The examination suggested the $\left(\mathrm{R}_{\mathrm{f}}\right)_{2} \mathrm{PCH}_{2} \mathrm{CH}_{2} \mathrm{P}\left(\mathrm{R}_{\mathrm{f}}\right)_{2}$ (dfepe, $\mathrm{R}_{\mathrm{f}}$ $=\mathrm{C}_{2} \mathrm{~F}_{5}$ ) ligand as a target. Roddick et al. have extensively studied this electron-deficient bis-phosphine for a wealth of intriguing Pt chemistry. ${ }^{26}$ This same group has also published the characterization of formally $\mathrm{Ni}^{0}$ complexes of dfepe, including (dfepe) $\mathrm{Ni}(\mathrm{CO})_{2}$, (dfepe) $\mathrm{Ni}(\mathrm{bpy})$, and (dfepe) $\mathrm{Ni}(\mathrm{COD})$, $\mathrm{COD}=1,5$-cyclooctadiene and bpy $=2,2^{\prime}$-bipyridine. ${ }^{26}$ The latter was structurally characterized, while the carbonyl complex was studied by analysis of the $\mathrm{CO}$ stretching frequencies; the latter study highlighted the electron-deficient nature of this bisphosphine, a property deemed to be beneficial in enhancing the nickel-amine BDE. To maintain the greatest degree of electronic and steric fidelity to the dfepe ligand, while minimizing the conformational complexity arising from the introduction of perfluoroethyl substituents, we replaced the $\mathrm{C}_{2} \mathrm{~F}_{5}$ groups of dfepe with $\mathrm{CF}_{3}$ to yield the dfmpe ligand $\left(\left(\mathrm{CF}_{3}\right)_{2} \mathrm{PCH}_{2} \mathrm{CH}_{2} \mathrm{P}\left(\mathrm{CF}_{3}\right)_{2}\right)$. ${ }^{31}$

Amination of CD-H by (dfmpe)Ni(NAr) was calculated using QM/MM methods analogous to those employed for the dtbpe systems. It was found that the enthalpy change for the formation of the metal-bound amine product is now exothermic and only mildly endergonic! The calculated amination enthalpy $\left(\Delta H_{\mathrm{am}}\right)$ for the dfmpe-based complex is $-13.4 \mathrm{kcal} / \mathrm{mol}$, with a corresponding free energy change of $+3.4 \mathrm{kcal} / \mathrm{mol}$.

As before, the thermodynamic changes were dissected into two steps: hydrogen atom abstraction and radical rebound. Interestingly, the HAA step changed relatively little in energetics upon dtbpe $\rightarrow$ dfmpe modification: $\Delta H_{\mathrm{HAA}}($ dtbpe $)=-1.3 \mathrm{kcal} /$ $\mathrm{mol} ; \Delta H_{\mathrm{HAA}}(\mathrm{dfmpe})=-5.7 \mathrm{kcal} / \mathrm{mol}$. However, there is a profound change in the rebound step upon going from the dtbpe ligand to the fluorinated dfmpe: $\Delta H_{\mathrm{reb}}($ dtbpe $)=+25.1 \mathrm{kcal} /$ $\mathrm{mol} ; \Delta \mathrm{H}_{\mathrm{reb}}(\mathrm{dfmpe})=-7.8 \mathrm{kcal} / \mathrm{mol}$. Thus, replacement of dtbpe with dfmpe leads to a nickel-nitrene complex for which both the HAA and rebound steps are now thermodynamically feasible.

(31) A crystal structure with the dfmpe ligand has been reported: Field, L. D.; Wilkinson, M. P. Organometallics 1997, 16, 1841. See also the following papers detailing syntheses and chemistry of dfmpe and its metal complexes: Murphy-Jolly, M. B.; Lewis, L. C.; Caffyn, A. J. M. Chem. Commun. 2005, 4479. Field, L. D.; Wilkinson, M. P. Tetrahedron Lett. 1992, 33, 7601. Phillips, I. G.; Ball, R. G.; Cavell, R. G. Inorg. Chem. 1988, 27, 4038. Burg, A. B.; Street, G. B. Inorg. Chem. 1966, 5, 1532. Burg, A. B.; Street, G. B. J. Am. Chem. Soc. 1963, 85, 3522. Cooper, P.; Fields, R.; Haszeldine, R. N. J. Chem. Soc. C 1971, 3031. Hoge, B.; Thosen, C. Inorg. Chem. 2001, 40, 3113. 


\section{Scheme 1}

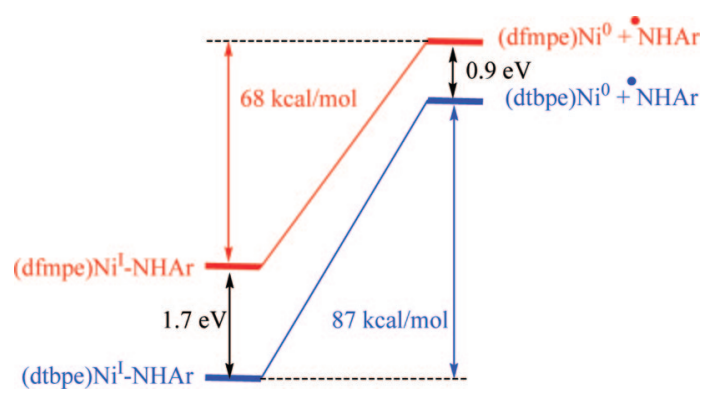

The significant change in the thermodynamics of amination upon replacement of dtbpe with dfmpe may presumably have both steric (e.g., dfmpe is less sterically constrained than dtbpe) and electronic (e.g., dfmpe is more electron-deficient than dtbpe) components, although we postulate that electronic factors are dominant, given the close structural similarity seen in analogous stationary points that differ only in the chelating phosphine. It was expected from acid-base arguments that the $\mathrm{Ni}$-amine bond energy would be increased by making the nickel a stronger Lewis acid in $\mathrm{Ni}$ (dfmpe) than in $\mathrm{Ni}$ (dtbpe). Indeed, dfmpe makes the nickel-amine bond energy more exothermic by $13.9 \mathrm{kcal} /$ mol, from 22.6 to $36.5 \mathrm{kcal} / \mathrm{mol}$.

The effect of introducing a more electron-deficient phosphine upon the $\mathrm{Ni}$-amide bond strength was a priori unclear. The QM/MM calculations predict that the nickel-amide bond strength is lowered upon replacement of dtbpe with dfmpe. The $\mathrm{Ni}$-amide bond enthalpy of $86.7 \mathrm{kcal} / \mathrm{mol}$ for (dtbpe) $\mathrm{Ni}-\mathrm{NHAr}$ is reduced to $67.7 \mathrm{kcal} / \mathrm{mol}$ for the corresponding $B D E$ of (dfmpe) Ni-NHAr, a $19.0 \mathrm{kcal} / \mathrm{mol}$ reduction in nickel-amide bond strength. Our hypothesis is that the difference in $\mathrm{Ni}-\mathrm{N}_{\text {amide }}$ BDEs is primarily a result of product stabilization in that $\mathrm{Ni}-\mathrm{N}$ homolytic scission, which entails the formal reduction of a $\mathrm{d}^{9}$ $\mathrm{Ni}^{\mathrm{I}}$ complex (amide) to a $\mathrm{d}^{10}-\mathrm{Ni}^{0}$ species (i.e., $\mathrm{Ni}(\mathrm{P} \sim \mathrm{P})$ ). The strongly $\pi$-acidic nature of the dfmpe is expected to more greatly stabilize the $\mathrm{d}^{10}$ product than its aliphatic-substituted counterpart, dtbpe. In support of this hypothesis, the difference in ionization potentials between the amide reactant and $\mathrm{Ni}(\mathrm{P} \sim \mathrm{P})$ product, as estimated employing Koopmans' theorem, is $0.8 \mathrm{eV}(22 \mathrm{kcal} /$ mol), nearly equal to the calculated difference in $\mathrm{Ni}-\mathrm{N}_{\text {amide }}$ BDEs $(\sim 19 \mathrm{kcal} / \mathrm{mol}$, Scheme 1$)$. The calculated HOMO and LUMO energies of dfmpe and dtbpe (extracted from the binding conformation of the nitrene complex) further highlight the substantial electronic impact of replacing the tert-butyl with trifluoromethyl substituents. The HOMO (P $\sigma$ lone pairs) and LUMO ( $\sigma^{*}$ PC acceptor orbital) are stabilized by 2.2 and $2.9 \mathrm{eV}$, respectively, upon going from dtbpe to dfmpe. The orbital energies highlight the greater $\pi$-acidity of dfmpe, but they also indicate that dfmpe is a weaker $\sigma$-donor, which may indicate some stability issues of the dfmpe ligand in a catalytic milieu.

The dtbpe-to-dfmpe substitution realizes $33 \mathrm{kcal} / \mathrm{mol}$ more driving force for radical rebound for the nickel complex with the fluorinated chelating bis-phosphine. Hence, the rebound step that was previously so enthalpically forbidding for dtbpe is now favorable with dfmpe ligation, $-7.8 \mathrm{kcal} / \mathrm{mol}$. Even with the unfavorable $T \Delta S$ term for radical rebound, the free energy change of this process is expected to be close to thermoneutral. Hence, from a thermodynamic viewpoint, (dfmpe)Ni(NAr) appears to be a feasible lead for further investigation as a hydrocarbon amination catalyst. Presumably, the steric and electronic differences between the present dfmpe model and
Roddick's dfepe ligand are small enough to also warrant consideration of (dfepe)Ni(NAr) for hydrocarbon amination. ${ }^{32}$

3. Closure of the Catalytic Cycle. While thermodynamic feasibility of amination of CD-H by (dfmpe)Ni(NAr) is an exciting first step in catalyst design, other issues must be addressed. First, it must be possible to generate (dfmpe)Ni(NAr) using common synthetic approaches in the literature. ${ }^{6-8}$ Second, it must be feasible to displace the amine product $(\mathrm{NH}(\mathrm{CD}) \mathrm{Ar}$ in our exercise) by reaction with a group-transfer reagent (i.e., $\mathrm{ArN}_{3}$ ) to regenerate the active nitrene species. Third, kinetic factors must be reasonable so as to permit a suitable reaction rate.

a. Product Displacement by Reaction with $\mathbf{A r N}_{3}$. Calculations indicate that formation of metal-bound amine product, NH(CD)Ar, from nitrene and substrate is feasible in a thermodynamic sense. However, for a useful catalytic system, the amine product must be removed from the inner coordination sphere of the Ni complex and the nitrene active species regenerated. The original account of the structural characterization of (dtbpe)Ni(NAr) involved a multistep synthesis from (dtbpe)N$\mathrm{iCl}_{2}$ starting material. ${ }^{5 \mathrm{a}}$ However, a recent report ${ }^{33}$ describes the synthesis of nickel-nitrenes with dtbpe supporting ligation via reactions of nickel starting materials with $\mathrm{ArN}_{3}$. As the amine is a neutral, labile ligand and the nickel in (dfmpe)N$\mathrm{i}(\mathrm{NH}(\mathrm{CD}) \mathrm{Ar})$ is formally $\mathrm{Ni}^{0}$, displacement of the amine by a group-transfer reagent such as $\mathrm{ArN}_{3}$ is suggested by literature precedent. $^{6-8}$

Regeneration of nitrene active species by amine displacement, eq 3 , is calculated to be highly exothermic, $\Delta H_{\text {reg }}=-36.7 \mathrm{kcal} /$ mol.

$$
\begin{aligned}
& (\text { dfmpe }) \mathrm{Ni}(\mathrm{NH}(\mathrm{CD}) \mathrm{Ar})+\mathrm{ArN}_{3} \rightarrow \\
& (\text { dfmpe }) \mathrm{Ni}(\mathrm{NAr})+\mathrm{N}_{2}+\mathrm{NH}(\mathrm{CD}) \mathrm{Ar}
\end{aligned}
$$

We have assumed ${ }^{6-8}$ that nitrene transfer (eq 3) will be kinetically facile, given its substantial thermodynamic driving force. Mechanistic studies of metal-mediated organic azide decomposition are rare, ${ }^{34}$ and further research in this direction, experimentally and computationally, would be welcome. A recent study from our laboratory ${ }^{35}$ on small models $\left(\mathrm{MeN}_{3}\right.$ and (dhpe) $\mathrm{Ni}(\mathrm{NMe})$, dhpe $\left.=\mathrm{H}_{2} \mathrm{PCH}_{2} \mathrm{CH}_{2} \mathrm{PH}_{2}\right)$ implicated a mechanism akin to that proposed by Proulx and Bergman ${ }^{34}$ (for Ta complexes) and showed the various intermediates and transition states for the metal-mediated azide decomposition by the $\mathrm{Ni}(\mathrm{P} \sim \mathrm{P})$ model to be kinetically quite feasible. Preliminary calculations indicate similar thermodynamics for Ni(dfmpe) + $\mathrm{ArN}_{3}$ reactions, as was seen in studies ${ }^{35}$ of a simpler model- $\mathrm{Ni}($ dhpe $)+\mathrm{MeN}_{3}$ - and implicate a pathway involving formation of a $\mathrm{Ni}(\mathrm{dfmpe})\left(\eta^{2}-\mathrm{N}_{3} \mathrm{Ar}\right)$ intermediate $(\Delta H=-44.0$ $\mathrm{kcal} / \mathrm{mol}$ ), which then rearranges and eliminates $\mathrm{N}_{2}$ via a nearly

(32) Using the methods described in the literature ( Cooney, K. D.; Cundari, T. R.; Hoffman, N. W.; Pittard, K. A.; Temple, M. D.; Zhao, Y. J. Am. Chem. Soc. 2003, 125, 4318) both $\mathrm{P}\left(\mathrm{CF}_{3}\right)_{3}$ and $\mathrm{P}\left(\mathrm{C}_{2} \mathrm{~F}_{5}\right)_{3}$ were found to have similar electronic and structural impacts.

(33) (a) "New routes to cationic nickel(III) imido complexes": Anderson, J. S.; Miller, A. J. M.; Iluc, V.; Hillhouse, G. L. Presented at the 37th Great Lakes Regional Meeting of the American Chemical Society, Milwaukee, WI, May 31-June 2, 2006; GLRM-340. (b) "New group transfer reactions of nickel-carbene and nickel-imido complexes": Harrold, N. D.; Waterman, R.; Hillhouse, G. L. Presented at the 233rd ACS National Meeting, Chicago, IL, March 25-29, 2007; INOR682.

(34) (a) Proulx, G.; Bergman, R. G. J. Am. Chem. Soc. 1995, 117, 6382. (b) Proulx, G.; Bergman, R. G. Organometallics 1996, 15, 684.

(35) Cundari, T. R.; Pierpont, A. W.; Vaddadi, S. J. Organomet. Chem. 2007, 692, 4551 (Erker Special Issue). 
barrierless, four-centered transition state and forms the products $\mathrm{N}_{2}+$ (dfmpe)Ni(NAr) $(\Delta H=-73.2 \mathrm{kcal} / \mathrm{mol})$.

b. Initial Generation of the (dfmpe)Ni(NAr) Active Species. Two main synthetic routes to generation of late transition metal-nitrenes have been used: displacement of a labile ligand by reaction with an organic azide, ${ }^{6-8}$ and a more involved route employed by Hillhouse et al. ${ }^{5 a}$ involving reactions with alkali metal reagents $\left(\mathrm{C}_{8} \mathrm{~K}\right.$ and LiNHAr), chemical oxidation (tropylium salt), and deprotonation by a sodium-bis(silyl)amide reagent. We have focused our initial efforts on organic azide syntheses. $^{6-8}$ A modeling study of the multistep Hillhouse synthesis for (dfmpe)Ni(NAr) is underway; gas-phase studies indicate the individual steps, and the aggregate mechanism, are exothermic, but the involvement of charged species implies that careful consideration of solvent effects is required.

Returning to our modeling of the synthesis of (dfmpe)Ni(NAr) by reaction of (dfmpe) Ni(LL), LL = labile ligand, with $\mathrm{ArN}_{3}$, we identified three candidates: ${ }^{26}$ (dfmpe) $\mathrm{Ni}(\mathrm{CO})_{2}$, (dfmpe)Ni(COD), and (dfmpe)Ni(bpy), all of which are models of experimentally characterized dfepe complexes. ${ }^{26}$ Most late metal-nitrene complex syntheses involve displacement of a monodentate ligand. Choice of these three candidates was motivated by the experimental reports of their syntheses; however, these are a very small subset of the possibilities suggested by the $\mathrm{CSD}^{30}$ for low-coordinate $\mathrm{Ni}^{0}$ complexes, including $\mathrm{LL}=$ dihapto-coordinated olefins, alkynes, ketones, arenes, benzyne, naphthalene, $\mathrm{C}_{6} \mathrm{~F}_{6}$, ArNCO, and carbodiimides.

ONIOM(B3LYP/6-31G(d):UFF) calculations were carried out for reaction 4 to model the thermodynamics of (dfmpe)Ni(NAr) formation, $\mathrm{LL}=(\mathrm{CO})_{2}, \mathrm{COD}$, and bpy, the latter two being bidentate ligands.

$$
(\text { dfmpe }) \mathrm{Ni}(\mathrm{LL})+\mathrm{ArN}_{3} \rightarrow(\text { dfmpe }) \mathrm{Ni}(\mathrm{NAr})+\mathrm{N}_{2}+\mathrm{LL}
$$

The competition between the strong $\pi$-acids dfmpe and $\mathrm{CO}$ does not sufficiently ameliorate the strength of the $\mathrm{Ni}-\mathrm{CO}$ bonds, as indicated by the QM/MM-calculated endothermicity of reaction $4\left(\Delta \mathrm{H}_{4}=+19.6 \mathrm{kcal} / \mathrm{mol}\right)$ for $\mathrm{LL}=\mathrm{CO}$. However, the other candidates, (dfmpe)Ni(COD) and (dfmpe)Ni(bpy), give displacement reactions for eq 4 that are calculated to be significantly exergonic: $\Delta \mathrm{G}_{4}(C O D)=-21.1 \mathrm{kcal} / \mathrm{mol}$ and $\Delta G_{4}($ bpy $)=-22.6 \mathrm{kcal} / \mathrm{mol}$.

c. Transition States for $\mathbf{C}-\mathbf{H}$ Bond Activation. Analysis of the literature ${ }^{1,3,6 a, 8}$ for $\mathrm{C}-\mathrm{H}$ bond activation by multiply bonded metal complexes suggests three plausible mechanisms for $\mathrm{C}-\mathrm{H}$ bond scission by (dfmpe)Ni(NAr): (a) direct [1+2] insertion; ${ }^{36}$ (b) a two-step mechanism involving [2+2] addition to yield a $\mathrm{Ni}^{\mathrm{II}}$-amide intermediate, (dfmpe)Ni(NHAr)(CD), which then undergoes reductive elimination to give the amine product, ${ }^{3,5,37,38}$ and (c) HAA to yield a Ni ${ }^{\mathrm{I}}$-amide complex, (dfmpe)Ni(NHAr), followed by radical rebound to give metal-bound amine product, (dfmpe)Ni(NH(CD)Ar). ${ }^{6 a, 8}$

Initial studies were carried out with small model substrates (methane) and ligands (dhpe $=\mathrm{H}_{2} \mathrm{PCH}_{2} \mathrm{CH}_{2} \mathrm{PH}_{2}$ ) to compare

(36) (a) Simmons, H. E.; Smith, R. D. J. Am. Chem. Soc. 1959, 81, 4256. (b) Long, J.; Yuan, Y.; Shi, Y. J. Am. Chem. Soc. 2003, 125, 13632 (c) Nakamura, M.; Hirai, A.; Nakamura, E. J. Am. Chem. Soc. 2003, 125, 2341. (d) Wang, D.; Zhao, C.; Phillips, C. L. J. Am. Chem. Soc. 2002, 124, 12903. (e) Charette, A. B.; Beauchemin, A. Org. React. 2001, 58, 1. (f) Fang, W. H.; Phillips, D. L.; Wang, D.; Li, Y. L. J. Org. Chem. 2002, 67, 154.

(37) Cundari, T. R.; Vaddadi, S. J. Mol. Struct. THEOCHEM 2006, 801 , 47.

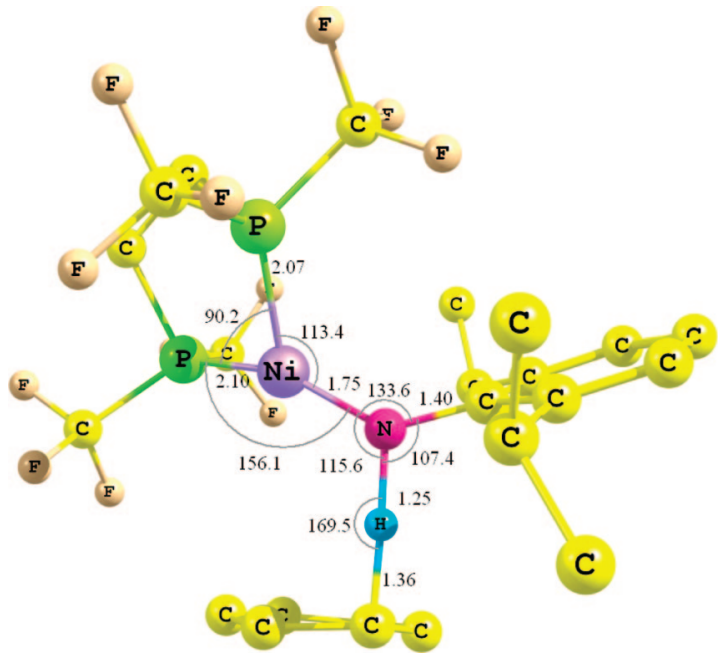

Figure 4. Calculated transition state for hydrogen atom abstraction (HAA) by (dfmpe)Ni(NAr).

the $[1+2]$ and $[2+2]$ mechanisms. ${ }^{35}$ Our calculations for a small nitrene model, (dhpe) Ni(NH), indicate that a single-step [1+2] (i.e., insertion) mechanism has a lower barrier than a two-step process (i.e., [2+2] addition and then reductive elimination). ${ }^{35}$ Constructing appropriate transition states from the $[1+2]$ and $[2+2]$ small models, and isolating the HAA transition state for full chemical models, indicates that hydrogen atom abstraction is the preferred pathway for $\mathrm{C}-\mathrm{H}$ activation of $\mathrm{CD}-\mathrm{H}$ by (dfmpe)Ni(NAr). Starting geometry optimizations from [1+2] and [2+2] transition-state guesses for activation of CD-H by the full (dfmpe)Ni(NAr) complex (despite the analysis of multiple starting conformations), all searches collapse to an HAA transition state. The single imaginary frequency (1148i $\mathrm{cm}^{-1}$ ) of the HAA transition state is characterized by movement of the hydrogen of the $\mathrm{C}-\mathrm{H}$ bond being activated from the $\mathrm{CD}-\mathrm{H}$ substrate to the nitrene nitrogen (Figure 4). The calculated nickel-nitrogen bond length in the transition state is $1.75 \AA$, ca. halfway between the calculated nickel-nitrogen bond lengths for the corresponding nitrene reactant $(1.66 \AA)$ and amide product (1.82 $\AA$ ). There is little change in the coordination of the dfmpe fragment in the transition state versus the nitrene reactant. The substrate approaches in a manner that is more parallel rather than normal to the $\mathrm{NiP}_{2} \mathrm{~N}$ coordination plane, inducing an asymmetry in the $\mathrm{P}-\mathrm{Ni}-\mathrm{N}$ bond angles, $113.4^{\circ}$ and $156.1^{\circ}$, in the HAA transition state (Figure 4). At this point, we are not in a position to discriminate whether the $\mathrm{H}$-atom transfer is a bona fide HAA or perhaps a proton-coupled electron-transfer (PCET) pathway. The present computational results indicating an HAA mechanism are given added interest by the recent paper by Bai and Stephan, ${ }^{39}$ which reports radical coupling chemistry via putative $\mathrm{Ni}$-imide complexes, although in those cases $\beta$-diketiminate ligation was utilized.

The calculated HAA transition state (Figure 4) is only 17.9 $\mathrm{kcal} / \mathrm{mol}$ (enthalpy) above the separate reactants, (dfmpe)Ni(NAr) and CD-H. Calculation of the intrinsic reaction coordinate (IRC) leads to a weakly bound adduct of the two reactants, bound by a mere $3.4 \mathrm{kcal} / \mathrm{mol}$ relative to the separate reactants.

(38) Koo and Hillhouse have identified $\mathrm{C}-\mathrm{N}$ bond formation via reductive elimination from nickel(alkyl)amido complexes, albeit with bipyridine supporting ligation: Koo, K.; Hillhouse, G. L. Organometallics 1995, 14, 4421. See also: Lin, B. L.; Clough, C. R.; Hillhouse, G. L. J. Am. Chem. Soc. 2002, 124, 2890, and ref $5 f$.

(39) Bai, G.; Stephan, D. W. Angew. Chem., Int. Ed. 2007, 46, 1856. 
The calculated enthalpic barrier of $17.9+3.4=21.3 \mathrm{kcal} /$ molfor the HAA transition state relative to the (dfmpe) $\mathrm{Ni}(\mathrm{NAr}) \cdot(\mathrm{CD}$ $H$ ) adduct seems reasonable in terms of a catalyst operating at near ambient conditions. Note that entropic considerations increase the calculated free energy of activation to $27.1 \mathrm{kcal} /$ mol.

The calculated IRC from the HAA transition state to the product side suggests that the products are the radical pair, (dfmpe)Ni(NHAr) and CD, and not an inserted amine product, (dfmpe)Ni(NH(CD)Ar), nor a square-planar complex, (dfmpe)$\mathrm{Ni}(\mathrm{NHAr})(\mathrm{CD})$. The radical pair is calculated by the QM/MM methods to be $-5.7 \mathrm{kcal} / \mathrm{mol}$ (enthalpy) below the separate reactants, (dfmpe)Ni(NAr) and CD-H. The square-planar complex, (dfmpe)Ni(NHAr)(CD), was generated independently and found to be $-12.8 \mathrm{kcal} / \mathrm{mol}$ more stable than the separate reactants and, hence, $7.1 \mathrm{kcal} / \mathrm{mol}$ more stable than the radical pair, (dfmpe) Ni(NHAr) + CD.

Given that the IRC indicates that the course of the reaction follows the pathway nitrene $+\mathrm{CD}-\mathrm{H} \rightarrow$ amide ${ }^{*}+\mathrm{CD}^{*}$, two subsequent routes from the amide intermediate to the amine product seem plausible. The first is formation of a $\mathrm{Ni}-\mathrm{C}$ bond to yield (dfmpe) Ni(NHAr)(CD), which then undergoes reductive elimination to produce the metal-bound product, (dfmpe)Ni$(\mathrm{NH}(\mathrm{CD}) \mathrm{Ar})$. The second possibility investigated is direct formation of a nitrogen-carbon bond by radical rebound. From the QM/MM calculations, the metal-bound amine product is $-13.4 \mathrm{kcal} / \mathrm{mol}$ in enthalpy relative to the separate reactants. Thus, formation of (dfmpe) Ni(NH(CD)Ar) is exothermic by 7.7 $\mathrm{kcal} / \mathrm{mol}$ from the radical pair (dfmpe) Ni(NHAr) $+\mathrm{CD}$ and exothermic by $0.6 \mathrm{kcal} / \mathrm{mol}$ relative to a square-planar $\mathrm{Ni}^{\mathrm{II}}$ intermediate (dfmpe) Ni(NHAr)(CD). Although we were unable to isolate a reductive elimination transition state connecting (dfmpe)Ni(NHAr)(CD) and (dfmpe)Ni(NH(CD)Ar), two observations are germane. First, one would expect steric factors to favor the rebound mechanism over the "metal rebound" mechanism, as the former would entail the formation of a less crowded three-coordinate, $\mathrm{Ni}^{0}$-amine product rather than a fourcoordinate, $\mathrm{Ni}^{\mathrm{II}}$ intermediate. Second, our model calculations suggest that reductive elimination from four-coordinate, $\mathrm{Ni}^{\mathrm{II}}$ intermediates is facile, ${ }^{35}$ and even if such an intermediate is formed, it is not expected to present an insurmountable kinetic impediment.

\section{Summary and Conclusions}

A computational chemistry study of a catalytic cycle for hydrocarbon amination has been performed to identify novel and promising systems for experimental study. A nickel-nitrene active species was chosen on the basis of the growing body of experimental research on this and similar late transition metal multiply bonded complexes. An existing system reported by the Hillhouse group ${ }^{5}$ was modified using a variety of criteria designed to maintain maximum overlap with experimentally reported nitrene complexes and feasible synthons thereof. Several intriguing results emanated from this first generation catalyst-design research. These are summarized here.

(1) Hydrogen atom abstraction (HAA) from 1,4-cyclohexadiene (CD-H) by (dtbpe)Ni(NAr) to form (dtbpe)Ni(NHAr) and cyclohexadienyl radical is calculated to be thermodynamically reasonable, $\Delta H_{\mathrm{HAA}}(\mathrm{dtbpe})=-1.4 \mathrm{kcal} / \mathrm{mol}$. However, the second step of the mechanism, radical rebound to form metalbound amine product, is highly endothermic $\left(\Delta H_{\text {reb }}(\mathrm{dtbpe})=\right.$ $+25.1 \mathrm{kcal} / \mathrm{mol}$ ).
(2) Analysis of $\mathrm{Ni}-\mathrm{N}$ bond enthalpies for nitrene, amide, and amine complexes suggests a weak nickel-nitrene $\pi$-bond of only $6 \mathrm{kcal} / \mathrm{mol}$. Thus, HAA is thermodynamically reasonable. For radical rebound, the endothermicity results from the $64.1 \mathrm{kcal} / \mathrm{mol}$ loss in $\mathrm{Ni}-\mathrm{N}$ bond enthalpy (from $\mathrm{Ni}$-amide to $\mathrm{Ni}$-amine) that is not compensated for by the weak $\mathrm{C}-\mathrm{N}$ bond formed.

(3) The present calculations, when combined with previous studies of $\mathrm{Ru}$ complexes, ${ }^{27}$ indicate that a possible route to thermodynamic feasibility for nickel-nitrene-mediated amination of $\mathrm{C}-\mathrm{H}$ bonds lies in identification of ligands that enhance the metal-amine bond strength while diminishing the metalamide bond strength. For the present purposes, the dfmpe ligand, dfmpe $=$ bis(di(trifluoromethyl)phosphino)ethane, was investigated.

(4) The calculated thermodynamics of (dfmpe)Ni(NAr)mediated amination of $\mathrm{CD}-\mathrm{H}$ indicate that the enthalpy change for the formation of the metal-bound amine product is now exothermic. Interestingly, the HAA step changed relatively little in energetics upon dtbpe to dfmpe modification, $\Delta H_{\mathrm{HAA}}(\mathrm{dfmpe})$ $=-5.7 \mathrm{kcal} / \mathrm{mol}$; however, there is a more profound energetic change in the rebound step, $\Delta \mathrm{H}_{\mathrm{reb}}(\mathrm{dfmpe})=-7.8 \mathrm{kcal} / \mathrm{mol}$. Thus, replacement of dtbpe with dfmpe leads to a $\mathrm{Ni}-$ nitrene for which both HAA and radical rebound are thermodynamically feasible.

(5) Regeneration of $\mathrm{Ni}-$ nitrene active species, (dfmpe) $\mathrm{Ni}$ (NAr), by reaction of the metal-bound amine product with $\mathrm{ArN}_{3}$ (plus loss of $\mathrm{N}_{2}$ ) is highly exothermic, $\Delta H_{\text {reg }}=-36.7 \mathrm{kcal} /$ mol. Likewise, two candidates for catalyst precursors, (dfmpe)$\mathrm{Ni}(\mathrm{COD})$ and (dfmpe) $\mathrm{Ni}(\mathrm{bpy})$, give nitrene-transfer reactions with $\mathrm{ArN}_{3}$ that are significantly exergonic, $\Delta G_{4}(\mathrm{COD})=-21.1$ $\mathrm{kcal} / \mathrm{mol}$ and $\Delta G_{4}(\mathrm{bpy})=-22.6 \mathrm{kcal} / \mathrm{mol}$.

(6) Constructing appropriate transition states for $\mathrm{C}-\mathrm{H}$ bond activation from corresponding [1+2] and [2+2] small models (i.e., phosphine and nitrene substituents set to hydrogen and methane as the substrate), plus isolating the HAA transition state for full chemical models, indicates that hydrogen atom abstraction is the preferred pathway for $\mathrm{C}-\mathrm{H}$ activation of $\mathrm{CD}-\mathrm{H}$ by (dfmpe)Ni(NAr). The calculated enthalpic barrier is $21.3 \mathrm{kcal} /$ mol relative to a weakly bound (dfmpe) Ni(NAr) $\cdot(\mathrm{CD}-\mathrm{H})$ adduct.

While the present results are encouraging, they are still preliminary. For example, the chosen substrate, $\mathrm{CD}-\mathrm{H}$, has a very weak $\mathrm{C}-\mathrm{H}$ bond, much weaker than more attractive hydrocarbon targets like methane and benzene. Moreover, no consideration of possible side reactions (e.g., aziridination of $\mathrm{CD}-\mathrm{H}$ ) has been made. Finally, the acid/base properties that make dfmpe viable may indeed make the ligand labile within a catalytic cycle such as envisaged here.

Despite these caveats, the present computations clearly suggest that late transition metal-nitrenes with fluorinated supporting ligation are promising candidates for catalytic amination of $\mathrm{C}-\mathrm{H}$ bonds. Further studies are underway in our laboratory, focusing on different supporting ligation in an attempt to isolate systems capable of aminating hydrocarbons with stronger $\mathrm{C}_{\mathrm{sp} 2}-\mathrm{H}$ (aromatic) and $\mathrm{C}_{\mathrm{sp} 3}-\mathrm{H}$ (aliphatic) bonds. Also, this work highlights a great need for efficient computational strategies for quantitative (i.e., $\pm 1-2 \mathrm{kcal} / \mathrm{mol}$ or better) calculation of energies for transition metal complexes and transition states, both of which are current research thrusts within our research laboratory. ${ }^{40,41}$

(40) Cundari, T. R.; DeYonker, N. J.; Peterson, K. A.; Steyl, G.; Wilson, A. K. J. Phys. Chem. A 2007, 111, 11269. 
Acknowledgment. The authors acknowledge the U.S. Department of Education for support of CASCaM, and the NSF for support of the UNT Chemistry Department computational chemistry facility (NSF-CRIF, grant CHE-0342824). This research is supported by a grant from the U.S. Department of Energy, Office of Basic Energy Sciences (to T.R.C.), Grant No.

(41) Grimes, T. V.; Cundari, T. R.; Wilson, A. K.; DeYonker, N. J. J. Chem. Phys. 2007, 127, 154117.
DE-FG02-03ER15387. Helpful discussions with Profs. Tim Warren (Georgetown), Pat Holland (Rochester), and Brent Gunnoe (NCSU) are gratefully acknowledged.

Supporting Information Available: Cartesian coordinates for calculated stationary points and complete ref 22 . This material is available free of charge via the Internet at http://pubs.acs.org.

JA803176J 